\title{
A Reestruturação do Sistema de Pagamentos Brasileiro e Seus Impactos nas Instituições Financeiras*
}

\author{
Alan Brito \\ Bacharel em Ciências Contábeis pela FEA/USP
}

Em 2002 devem ocorrer algumas mudanças significativas no Sistema de Pagamentos Brasileiro, em decorrência de decisões tomadas pelo Banco Central do Brasil, com o objetivo de aperfeiçoar os mecanismos de pagamentos na economia brasileira.

Se estas modificações ocorrerem como o previsto, conduzirão a alterações no funcionamento do sistema financeiro.

O objetivo deste presente documento é contribuir para o entendimento da natureza daquelas mudanças, sugerir seus prováveis impactos para o mercado financeiro e analisar as principais vantagens e desvantagens decorrentes da implementação do novo Sistema de Pagamentos Brasileiro.

Palavras-chave: Sistemas de Liquidação pelo Valor Líquido Diferido, Sistemas de Liquidação pelo VaIor Bruto em Tempo Real, Irrevocabilidade e incondicionalidade dos pagamentos, Câmaras de Liquidação.

INTRODUÇÃO

O setor bancário está passando por uma significativa transformação, impulsionada pela iniciativa do Governo de reestruturar o Sistema de Pagamentos Brasileiro.

Em linhas gerais, sistema de pagamentos pode ser entendido como sendo um conjunto de normas, padrões e instrumentos que comandam a transferência de valores entre os vários agentes econômicos (empresas privadas, indivíduos, bancos, governo, etc.),
Some significant changes are expected to occur in the Brazilian Payments System, in view of the Brazilian Central Bank's intent to perfect the country's current payment mechanism.

If these modifications take place as predicted, they will lead to alterations in the way the country's financial system operates.

The purpose of this report is to make a contribution to the understanding of the nature of these changes, evaluate the probable consequences for the financial market and examine the principal advantages and disadvantages of the new Brazilian Payment System's implementation.

Key words: Deferred Net Settlement Systems, Real Time Gross Settlement Systems, Finality, Clearing Houses.

utilizados principalmente pelas instituições financeiras para transferir fundos do pagador para o recebedor e, com isso, encerrar uma obrigação, tanto em moeda nacional quanto em moeda estrangeira.

Diariamente, o montante das transferências de ordens (na sua maioria, realizadas por meio de cheques, cartões de crédito, transferências eletrônicas de fundos e documentos de créditos) é transformado em poucas transferências interbancárias de fundos de alto valor nas contas reservas bancárias que cada banco mantêm no Banco Central. Como resultado dessas

\footnotetext{
* Este artigo corresponde ao trabalho de Monografia, apresentado para a conclusão do Curso de Ciências Contábeis da FEA/USP - Ano 2001, tendo como orientador o Prof. Dr. Iran Siqueira Lima, do Depto de Contabilidade e Atuária - FEA/USP.
} 
transferências, desequilibra-se o fluxo de caixa dos bancos nas reservas bancárias, criando condições para o funcionamento de mercado interbancário de reservas, cujas transações também cursam no sistema de pagamentos.

O pagamento de um banco é a liquidez do outro. Problemas na transferência de fundos, qualquer que seja a razão, podem levar à inadimplência de outros participantes, que deles dependiam para equilibrar seus caixas (BCB, 1999).

Em face desses acontecimentos, o Banco Central deparou com um grande dilema: ele deve devolver os lançamentos a descoberto na conta reservas bancárias, aceitando as possíveis conseqüências, ou deve fornecer liquidez, mesmo que na forma de saque a descoberto, para dar curso à cadeia de pagamentos?

Este se tornou o grande dilema do Banco Central do Brasil, para cuja solução desenvolveu o projeto de reestruturação do sistema de pagamentos brasileiro.

Diante dessa situação, em junho de 1999, a diretoria do Banco Central do Brasil, com a missão de zelar pelo bom funcionamento e integridade do sistema financeiro, aprovou o projeto de reestruturação do sistema de pagamentos brasileiro, visando a aumentar a eficiência e melhorar os controles de riscos no Sistema Financeiro Nacional.

O projeto de reestruturação do sistema de pagamentos é extremamente amplo, contemplando desde mudanças em aspectos operacionais e regulatórios das instituições financeiras, até a alteração da ordem de preferência de credores de instituições financeiras insolventes previamente estabelecidas. Além disso, modificará o cotidiano dos órgãos reguladores e dos agentes financeiros e não-financeiros, criará novas oportunidades de negócios, viabilizará novos serviços e, acima de tudo, transformará a infra-estrutura de pagamentos, com possíveis impactos no fluxo de entrada e saída de recursos externos, na condução da política monetária e na avaliação, pela comunidade internacional, do "risco país".

O Banco Central do Brasil pretende adotar uma eficiente estrutura para a realização de pagamentos e liquidação de operações financeiras, através de um sistema de pagamentos desenhado para poder resistir à quebra de um ou mais participantes, minimizando o risco sistêmico.

Nesse contexto, o objetivo do presente trabalho é demonstrar a extrema importância do processo de reestruturação do sistema de pagamentos brasileiro, atualmente em curso no país, e apontar seus possíveis impactos nas instituições financeiras.

\section{REQUISITOS DE UM SISTEMA DE PAGAMENTOS}

Sistema de pagamentos é o conjunto de procedimentos, regras, instrumentos e sistemas operacionais integrados, usados para transferir fundos do pagador para o recebedor e, com isso, encerrar uma obrigação. Economias de mercado dependem desses sistemas para movimentar os fundos decorrentes da atividade econômica (produtiva, comercial e financeira), tanto em moeda local quanto em moeda estrangeira (BCB, 1999, p.1).

Ele é um componente indispensável do que se poderia denominar de infra-estrutura financeira, essencial para o adequado funcionamento de qualquer economia de mercado que dependa da liquidação diária de milhares de transações decorrentes das compras/ vendas de bens, serviços e ativos.

Desta forma, um requisito importante de um sistema de pagamentos é a certeza de liquidação de pagamentos efetuados por meio de sua rede de participantes. A transferência de fundos cursados no sistema de pagamentos deve ser final, irrevogável e incondicional. Em última análise, estas condições serão observadas quando a transferência de fundos ocorrer nas contas de reservas bancárias que os bancos comerciais mantêm no Banco Central.

Além disso, duas outras características são desejáveis em um bom sistema de pagamentos: integridade e eficiência. A primeira delas refere-se ao fato de que o funcionamento do conjunto depende da operação de cada um de seus componentes, pois uma faIha em cada subsistema pode comprometer o todo, colocando em risco a confiança da sociedade nos mecanismos de pagamentos, o que pode causar profundas repercussões econômicas. A eficiência diz respeito à efetividade em termos dos custos econômicos que são incorridos para a execução das funções típicas do sistema de pagamentos.

$O$ desenho de uma rede de pagamentos deve contemplar principalmente a redução dos riscos inerentes ao seu funcionamento, entre os quais sobressaem os riscos de liquidação. Estes, por sua vez, compreendem o risco de crédito e o risco de liquidez. O primeiro 
refere-se à possibilidade de uma das contrapartes de uma transação não cumprir suas obrigações no prazo estabelecido ou em nenhum período posterior. De outro lado, o risco de liquidez resulta do não cumprimento de uma obrigação, por um dos participantes de uma transação no prazo estabelecido, mas que será cumprida em um momento qualquer após a data preestabelecida, podendo resultar em prejuízos para o segundo participante da transação. Além dos demais tipos de riscos que podem afetar um sistema de pagamentos (operacional, legal, etc.), existe o risco sistêmico, fonte de preocupação cotidiana dos bancos centrais, que pode dar origem a riscos entre fronteiras.

Estes fatores têm estimulado um movimento recente no sentido de adaptação dos sistemas nacionais de pagamentos às melhores práticas internacionais. A redução do risco sistêmico tem sido, provavelmente, a principal motivação do Banco Central para proceder às modificações no sistema nacional de pagamentos, sobretudo após as inúmeras dificuldades experimentadas pelo sistema bancário brasileiro de adaptação a um ambiente de taxa de inflação civilizada (MOURA, 2000, p.08-09).

O Banco Central do Brasil desempenha um papel fundamental no processo de reestruturação do sistema de pagamentos brasileiro, possuindo as atribuições de zelar pelo bom funcionamento e integridade do sistema financeiro e conduzir adequadamente a política monetária nacional.

\section{Modelo internacional}

O Comitê de Sistemas de Pagamentos e de Liquidação (CSPL) dos Bancos Centrais dos países do Grupo dos Dez (G10), órgão vinculado ao Banco de Compensações Internacionais - BIS, estabeleceu, em Maio de 1998, uma força tarefa para trabaIhar em um documento que pudesse condensar as melhores práticas e os preceitos mínimos dos sistemas de pagamentos nos diversos países. Esta força tarefa não se limitou apenas aos representantes dos bancos centrais do G10 mas contou também com a contribuição de representantes de mais 11 outros bancos centrais de países em diferentes estágios de desenvolvimento.

O objetivo final, alcançado em julho de 2000, está resumido no documento Core Principles for Systemically Important Payment Systems e tem ser- vido de base para o desenvolvimento de sistemas de liquidação em diversos países no mundo. Core Principles é um documento generalista que elenca as melhores práticas que devem ser adotadas no desenho e na operacionalização dos sistemas de pagamentos. Neste sentido, o documento funciona como um guia, sem ter como base nenhum sistema em particular, a ser adotado pelos países que tencionam desenvolver seus sistemas financeiros.

Os princípios fundamentais dos sistemas de pagamentos sistematicamente importantes estão elencados abaixo:

$\rightarrow$ O sistema deve estar fundamentado em sólida base legal, incontestável nas diversas esferas;

$\rightarrow$ Suas regras e procedimentos devem propiciar aos participantes claro entendimento de seus riscos;

$\rightarrow$ O sistema deve definir claramente como serão geridos os riscos de crédito e de liquidez, especificando as responsabilidades de seu operador e dos participantes, com incentivos adequados ao gerenciamento e ao controle/redução dos riscos;

$\rightarrow$ O sistema deve promover a liquidação final e irrevogável dos pagamentos na sua data de liquidação, ao longo do dia ou, no limite, no final do dia;

$\rightarrow$ Os sistemas de liquidação diferida pelo valor multilateral devem ser capazes de assegurar o pontual cumprimento das liquidações diárias, na hipótese de incapacidade de liquidação do participante com a maior obrigação;

$\rightarrow$ Os ativos utilizados para liquidação nos sistemas de pagamentos devem preferencialmente representar direitos contra o Banco Central ou, no caso de utilização de outros recursos, os mesmos devem conter risco de crédito e de liquidez pequeno ou inexistente;

$\rightarrow$ O sistema deve assegurar alto grau de segurança e credibilidade operacional, além de contar com procedimentos de contingência para pontual finalização do processamento diário;

$\rightarrow$ O sistema deve prover mecanismos simples e eficientes para a execução de pagamentos a todos os usuários e à economia;

$\rightarrow$ O sistema deve ter critérios objetivos e públicos para participação, permitindo acesso aberto e justo; 
$\rightarrow$ A governança do sistema deve ser eficaz, responsável e transparente.

No mesmo documento estão também elencadas as principais responsabilidades das autoridades monetárias no processo de aplicação dos princípios fundamentais:

$\rightarrow$ A autoridade monetária é responsável pelo desenho do sistema de pagamentos e deve deixar claros seus objetivos;

$\rightarrow$ A autoridade monetária é responsável por garantir a eficiência e a segurança dos sub-sistemas sistemicamente importantes;

$\rightarrow$ Sistemas de pagamento consomem recursos substanciais. Deve haver equilíbrio entre a necessidade de segurança do sistema e seus custos;

$\rightarrow$ A autoridade monetária deve garantir que todos os sub-sistemas operam de acordo com os princípios fundamentais.

Mesmo antes da publicação desse documento pelo BIS, diversos países, principalmente na América do Norte e Europa, vêm se empenhado em desenvolver sistemas de pagamentos seguros que possibilitem a redução do risco sistêmico em suas economias.

Neste sentido, diversos sistemas de liquidação bruta em tempo real (LBTR) e de liquidação diferida pelo liquido (LDL) estão funcionando e vêm sendo aperfeiçoados no mundo:

- Sistemas LBTR (Liquidação Bruta em Tempo Real):

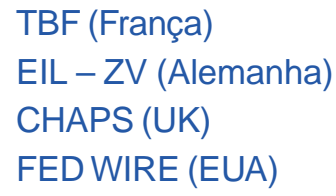

- Sistemas LDL (Liquidação Diferida pelo Liquido):

$$
\begin{aligned}
& \text { CHIPS (EUA) } \\
& \text { EAF- (Alemanha) } \\
& \text { SNP (França) } \\
& \text { Zengin (Japão) }
\end{aligned}
$$

A maioria dos sistemas já segue os princípios fundamentais e incorporam mecanismos de mensuração de risco e de repartição de perdas bastante sólidos.

\section{Sistemas de liquidação pelo valor bruto em tempo real (LBTR)}

Durante a década passada, muitos países pertencentes ou não ao Grupo dos Dez introduziram sistemas de Liquidação pelo Valor Bruto em Tempo Real (LBTR) para transferências de fundos de grandes valores. Os sistemas LBTR executam a liquidação definitiva de transferências interbancárias de fundos em bases contínuas, transação a transação, ao longo do processamento diário. Os sistemas LBTR são tipicamente sistemas eletrônicos que utilizam redes de telecomunicações, as quais transmitem e processam informações em tempo real.

Por conta da crescente importância da LBTR, o CSPL instituiu um Grupo de Estudos para identificar e analisar as principais questões relacionadas com a operação de tais sistemas.

Este grupo de estudos consolidou informações sobre as características dos principais sistemas LBTR em operação e as forneceu a um vasto público, incluindo as autoridades monetárias dos países atualmente em processo de introdução ou desenvolvimento de sistemas LBTR, bem como a segmentos econômicos interessados no aperfeiçoamento dos controles de riscos em sistemas de pagamentos e de liquidação.

O Grupo Ad Hoc de Estudos de LBTR estabelecido pelo Comitê de Sistemas de Pagamentos e Liquidação (CSPL) concentrou-se na análise das seguintes questões:

- Liquidez;

- Sistemáticas de enfileiramento;

- Estruturas do fluxo de mensagens e de informações;

- Questões originadas do inter-relacionamento entre os sistemas LBTR e outros sistemas de liquidação;

- Implicações na política monetária; e

- Diferenças entre os sistemas LBTR e os sistemas de liquidação pelo valor líquido.

Os resultados deste trabalho estão consolidados no documento publicado em março de 1997 pelo BIS: Real Time Gross Settlement Systems.

Os sistemas LBTR podem contribuir para limitar substancialmente os riscos do sistema de pagamentos como um todo. A capacidade de transferência definitiva, contínua e intradia dos sistemas LBTR pode minimizar ou mesmo eliminar os riscos interbancários 
básicos no processo de liquidação. Mais especificamente, os sistemas LBTR podem reduzir substancialmente a duração das exposições a riscos de crédito e de liquidez.

Nesse sistema a liquidação ocorre pelo valor bruto (uma a uma) e em tempo real, isto é, a sensibilização das reservas bancárias dos envolvidos é imediata. Com isso, é possível eliminar o "lag" de liquidação, juntamente com o risco de crédito, garantindo a finalização dos pagamentos ao longo do dia e, com isso, reduzir o potencial de risco sistêmico (BCB, 1999 p.9).

Considerando que a fonte primária dos riscos mencionados é a defasagem de tempo entre a contração e a liquidação da operação ("lag" de liquidação), os LBTR geram substancial conforto a seus participantes. Uma vez efetuada a liquidação no LBTR, os bancos recebedores podem creditar os fundos para seus clientes, usá-los em finalidades próprias ou em outros sistemas de liquidação, sem enfrentar o risco de regresso ou cancelamento. Esta capacidade possibilita a transferência em tempo real de fundos irrevogáveis e incondicionais a outros sistemas de liquidação, propiciando a redução do risco do sistema como um todo.

\section{Sistemas de liquidação pelo valor líquido diferido (LDL)}

Em um sistema de compensação pelo valor líquido, a liquidação das transferências de fundos ocorre em um momento pré-determinado pelo valor líquido de cada participante. A posição líquida de cada um dos bancos participantes é calculada, seja em bases bilaterais, seja em bases multilaterais, como a soma dos valores de todas as transferências que ele recebeu até uma determinada hora, menos a soma dos valores de todas as transferências que ele enviou. A posição líquida na hora da liquidação é chamada de posição líquida de compensação.

Atualmente, os sistemas de liquidação pelo valor líquido nos países do G-10 são, em sua maioria, sistemas de compensação multilateral. Os referidos sistemas são tipicamente sistemas de liquidação de final do dia, promovendo a liquidação por meio de transferências entre as contas das instituições financeiras no Banco Central.

Nesse sistema, as instruções de pagamento são liquidadas ao final do período com a transferência do valor líquido multilateral dessas instruções. A principal vantagem de sistemas DNS (Deferred Net Settlement) é a baixa demanda por reservas bancárias, pois a compensação multilateral dos valores entre os participantes reduz o volume de recursos a serem transferidos. A defasagem de tempo na liquidação cria a concessão implícita de crédito do banco recebedor para o banco pagador, o que expõe os participantes ao risco de crédito (BCB, 1999, p. 07).

Uma vez que nos sistemas LDL a liquidação da operação é diferida em relação ao horário de contratação, o risco de liquidez é substancialmente maior que nos sistemas LBTR. Neste sentido, é importante estabelecer mecanismos para minimizar tal risco. O estabelecimento de limites para os participantes, a colaterização de garantias e constituição de fundos são alguns desses mecanismos.

\section{Tipos e fontes de riscos em sistemas de pagamentos}

Outros relatórios preparados pelo CSPL identificaram os principais tipos de riscos em sistemas de pagamentos. O risco de crédito e o de liquidez são dois riscos básicos aos quais os participantes dos sistemas de liquidação e pagamento estão expostos.

\section{- Risco de Crédito}

O risco de crédito decorre quase sempre da inadimplência de uma contraparte e resume-se no risco de uma contraparte não honrar uma obrigação pelo seu valor total, seja no vencimento, seja em qualquer data posterior. Ele pode ser de duas naturezas:

- Risco de perda de receitas não realizadas em virtude de contratos não liquidados na data valor (risco de custo de reposição);

- Risco de perda do valor integral da transação (risco de principal).

\section{- Risco de Liquidez}

O risco de liquidez consiste no risco de uma contraparte não liquidar, total ou parcialmente, uma obrigação no vencimento. O risco de liquidez afeta desfavoravelmente a posição de liquidez projetada do credor. $\mathrm{O}$ atraso no recebimento pode forçar o credor a cobrir a deficiência no fluxo de caixa mediante financiamento de curto prazo de outras fontes, resul- 
tando em perda financeira, além de eventuais danos de imagem. Em casos extremos, o credor pode encontrar-se incapacitado para cobrir sua deficiência e, por conseguinte, ficar também incapaz de atender suas obrigações perante terceiros.

\section{- Risco de Liquidação}

O risco de liquidação é o risco de que o processamento ou a liquidação de transações individuais não aconteçam conforme esperado. Risco de liquidação de um pagamento compreende o risco de crédito e o risco de liquidez. Dois componentes importantes deste risco são:

a) a defasagem ou o intervalo entre a execução da transação e seu processamento definitivo ("lag" de liquidação), e

b) a defasagem entre os processamentos dos dois segmentos da transação, ou seja, o intervalo entre o pagamento e a entrega.

\section{a) Defasagem de tempo entre a contração e a liquida- ção das operações ("lag" de liquidacão).}

A defasagem de tempo entre a contratação e a liquidação de uma operação eleva a possibilidade de que um banco possa tornar-se ilíquido e falhar na liquidação de suas obrigações na data de vencimento ou em data futura. O risco de liquidez é tanto maior quanto maior for o "lag" de liquidação. A defasagem de tempo entre a contratação e a liquidação das operações pode contaminar todo o mercado, levando ao risco sistêmico.

Enquanto a liquidação definitiva não ocorrer, qualquer atividade de pagamento subjacente com os fundos "não liquidados" permanece condicional. Por exemplo, por conta de pressões competitivas e demanda dos clientes, os bancos podem adiantar fundos para seus clientes, baseados no recebimento de mensagens de pagamento, antes do efetivo ingresso dos recursos. Os bancos recebedores de tais fundos ficam, por sua vez, expostos ao risco de principal porque, caso a primeira liquidação não ocorra, eles terão estornadas as transferências recebidas.

\section{b) Entrega contra pagamento (DVP)}

O Risco de DVP (delivery versus payment), entrega contra pagamento, consiste no risco de se entregar um ativo sem que o outro ativo, no caso o pagamento, seja disponibilizado imediatamente.

As câmaras de liquidação de compensação LDL são particularmente sensíveis a este risco na medida em que dependem do recebimento de fundos e ativos de todos os devedores para efetuar o pagamento aos credores. Nas câmaras de liquidação LBTR, este risco é minimizado pelo fato de os pagamentos e a entrega ocorrerem em bases individuais e simultâneas. Neste sentido, a agilidade no processamento da liquidação, a segurança e os mecanismos de contingência operacional são cruciais para todas as câmaras de liquidação. Particularmente para as "LDLs" é ainda extremamente desejável que o processamento da liquidação (recebimento de todos os credores para pagamento aos devedores) seja concluído no menor tempo possível.

\section{O ATUAL SISTEMA DE PAGAMENTOS BRASILEIRO}

Para a liquidação das obrigações resultantes de transações com bens, serviços e ativos, a economia brasileira conta com um conjunto de subsistemas de transferência de fundos e de movimentação de títulos e valores mobiliários entre seus participantes.

Por intermédio desta rede de pagamentos, são liquidadas as operações com títulos públicos e privados, ações e derivativos, e efetuadas as transferências de fundos em moeda nacional e em moeda estrangeira. O Sistema de Pagamentos atual é composto por quatro câmaras de compensação (Selic, Cetip, Compe e Câmbio) que liquidam diretamente nas contas reservas bancárias no Banco Central.

Em nenhuma delas há mecanismos de gerência de riscos capaz de absorver a insolvência de um de seus participantes. De modo geral, as mensagens de liquidações financeiras enviadas por elas ao Banco Central não são criticadas quanto a saldo, sendo possível a manutenção de saques a descoberto ao longo do dia na expectativa de acerto do saldo com lançamento de outra origem (BCB, 1999, p. 4).

As câmaras de compensação são encarregadas da liquidação de operações contratadas pelas instituições financeiras, o que ocorre através de lançamentos nas contas Reservas Bancárias mantidas pelas instituições financeiras junto ao Banco Central do Brasil. 


\section{Composição do sistema de pagamentos brasileiro}

Como mencionado, o sistema brasileiro atual é composto por quatro sistemas que liquidam diretamente nas contas de reservas bancárias junto ao Banco Central:

- Selic (Títulos Públicos)

- Cetip (Títulos Privados)

- Compe (Cheque e outros), e

- Câmbio

\section{Selic - Sistema Especial de Liquidação e Custódia}

O SELIC é o sistema responsável pela liquidação das operações envolvendo títulos públicos federais e alguns títulos estaduais e municipais, realizadas no mercado de balcão. Esse sistema realiza as transações, primárias e secundárias, envolvendo títulos públicos federais, e as transações de compra ou de venda de um certificado de depósito interbancário.

Todos os títulos negociados nesse sistema são desmaterializados (escriturais) e custodiados em nome de seus possuidores. A liquidação financeira é defasada e pelo valor líquido multilateral (LDL), acontecendo às 23 horas do mesmo dia da negociação.

Para evitar o risco de principal, as confirmações ocorrem por meio de mecanismo de entrega contra pagamento, em que a transferência de custódia está atrelada à mensagem de liquidação financeira específica (BCB, 1999).

\section{Cetip - Central de Custódia e de Liquidação Financeira de Títulos}

Este sistema é semelhante ao Selic, porém destinado à negociação de títulos privados e de alguns títulos públicos.

A liquidação é defasada e é processada pelo valor líquido multilateral, acontecendo às 16 horas do dia seguinte à negociação. Também está baseado em um mecanismo de entrega contra promessa de pagamento. Além disso, é via movimento da Cetip que as mensagens de liquidação financeira das Bolsas de Valores (CBLC) e da BM\&F são encaminhadas para sensibilização da conta Reservas Bancárias. Nas transações em bolsas, o "lag" de liquidação é de cinco dias, fora do padrão internacional (três dias) (BCB,1999).

\section{Compe - Serviço de Compensação de Cheques e Outros Papéis}

É o sistema responsável pela compensação de cheques e outros papéis como os Documentos de Ordem de Crédito - DOC's e as Fichas de Compensação de Bloquetos de Cobrança.

A liquidação é defasada e é processada pelo valor líquido multilateral, acontecendo no dia seguinte ao da compensação, no caso de cheques de valor igual ou superior a determinado limite (atualmente estabelecido em $R \$ 300,00)$. Como no desenho atual não há sistema específico para transferência interbancária de fundos de grande valor, no movimento da Compe os grandes valores misturam-se com pequenas operações (cheques de pequeno valor) (BCB, 1999).

\section{Câmbio - Sistema de Câmbio}

O Sistema de Câmbio destina-se à liquidação das operações em moeda estrangeira. As operações de câmbio no mercado interbancário são liquidadas por um sistema administrado pelo Banco Central, onde são realizadas as transações interbancárias com moeda estrangeira. A liquidação da moeda nacional é defasada e processada pelo valor bruto (uma a uma) e geralmente acontece dois dias depois da negociação. A liquidação em moeda nacional é feita através do registro no Sisbacen para a sensibilização das contas de reservas bancárias das partes, e a liquidação em moeda estrangeira é efetuada fora do sistema, pelas contrapartes das operações, uma a uma, no exterior.

\section{Aspectos negativos do sistema atual}

São as seguintes as fontes de Risco do Atual Sistema de Pagamentos Brasileiro:

\section{a) O saldo da conta de reservas bancárias não é verificado no intradia.}

As mensagens de liquidação financeiras enviadas pelas câmaras de liquidação privadas e pelo Banco Central não são processadas em tempo real. 
O processamento é feito por lotes e acontece apenas ao final do dia, o que torna impossível a crítica em relação ao saldo da instituição ao longo do dia.

Neste sentido, torna-se possível a manutenção de saldos a descoberto ao longo do dia na expectativa de acerto com lançamento de outra origem.

b) As câmaras de liquidação privadas não possuem mecanismos de gerência de risco capazes de absorver a insolvência de pelo menos um de seus participantes.

A ausência de mecanismos de gerência de risco leva à condicionalidade dos pagamentos. Na hipótese de insolvência de um participante, a câmara poderá estornar os fundos que foram transferidos pelo insolvente a outros participantes.

\section{c) Suposição de liquidação financeira certa pa-} trocinada pelo Banco Central.

Devido à incapacidade de absorção de perdas pelas câmaras de liquidação, o Banco Central evita devolver lançamentos a descoberto dos participantes pelo temor de que esta devolução provoque uma crise sistêmica.

Neste sentido, o Banco Central assume o elo ocupado pelo Banco inadimplente na cadeia de pagamentos, ou fornece liquidez através de operações subsidiadas. O risco moral deste comportamento é altíssimo, como foi observado nos questionamentos às operações de venda de dólares aos bancos Marka e FonteCindam em janeiro de 1999.

Adicionalmente, a certeza de liquidação das operações remove o incentivo dos bancos na avaliação dos riscos de contraparte. O desconhecimento dos riscos pode elevar o grau de exposição dos bancos, tornando-os mais agressivos, o que, por sua vez, também contribui para elevar o potencial de crises sistêmicas.

d) Ausência de regras claras e escritas sobre riscos incorridos pelos participantes da cadeia de pagamentos.

Na ótica dos investidores estrangeiros, a ausência de regras escritas para a absorção dos riscos, seja pelo Banco Central seja pelos participantes, impossibilita a mensuração dos riscos envolvidos nas aplicações financeiras no Brasil. Esta incerteza tende a elevar o prêmio requerido nas operações finan- ceiras, criando obstáculos ao pleno desenvolvimento dos mercados e, em última instância, da economia (Custo Brasil).

e) Elevada defasagem de tempo entre a contratação e a liquidação das operações lag de liquidação.

Devido à condicionalidade dos pagamentos, temos elevado lag de liquidação nas Bolsas.

No caso específico da Bovespa, a defasagem entre a data de contratação e a data de finalização da "entrega contra pagamento" chega a cinco dias. Novamente, perde-se competitividade, dado que o padrão internacional é de três dias.

\section{f) Ausência de um sistema específico para pa- gamentos críticos.}

No Brasil, a grande maioria dos pagamentos são cursados via Compe. Como já foi visto anteriormente, os pagamentos de grandes valores devem cursar por sistemas protegidos do tipo LBTR. A criação de um sistema LBTR permite a redução dos riscos de liquidação das câmaras de liquidação, propiciando maior conforto a todo o sistema.

\section{g) Base legal}

A legislação societária atual não reconhece a compensação multilateral fundamental para o estabelecimento do processo de novação das câmaras de liquidação. Novação é o mecanismo contratual pelo qual as câmaras de liquidação podem se interpor como responsáveis por assegurar a finalização de uma transação entre duas partes. Adicionalmente, a lei de falências prevê como preferenciais os créditos trabaIhistas, entre outros, aos pagamentos cursados nas câmaras de liquidação.

\section{Aspectos positivos do sistema atual}

O desenho atual de nosso sistema de pagamentos possui alguns aspectos positivos:

- Há ampla automatização dos processos, reduzindo o tempo de processamento;

- Os títulos negociados são todos desmaterializados, permitindo sistema de custódia eletrônica, que é mais ágil e de menor custo;

- A base tecnológica de telecomunicações atende plenamente às necessidades; 
- As câmaras de liquidação existentes funcionam operacionalmente de modo adequado.

Ao longo dos anos de montagem do sistema de pagamentos, houve parceria entre o Banco Central e o mercado na busca de um sistema mais eficiente. Espera-se que tal parceria continue na transformação para um sistema ainda mais seguro.

\section{O NOVO SISTEMA DE PAGAMENTOS} BRASILEIRO

Além da adoção de padrões internacionais, o objetivo final das mudanças que estão sendo implementadas com o novo Sistema de Pagamentos Brasileiro é a assunção pelo mercado dos riscos inerentes ao funcionamento do próprio mercado e a conseqüente redução do risco assumido atualmente pelo Banco Central.

As principais diretrizes do novo sistema de pagamentos estão definidas logo abaixo:

\section{$\rightarrow$ Definição do papel do Banco Central}

Compete ao Banco Central assegurar o adequado desenho do sistema. Deste modo, o Banco Central é responsável pela gerência e operacionalização das contas de reservas bancárias, assim como pelo estabelecimento dos requisitos mínimos a serem observados pelas câmaras de liquidação que pretendam dar curso à liquidação de suas transações diretamente nas contas de reservas.

Igualmente, cabe ao Banco Central monitorar o adequado gerenciamento dos riscos por parte de todos os participantes.

\section{$\rightarrow$ Redução do risco de crédito do Banco Central}

A conta de reservas bancárias terá seu regime operacional alterado com verificação do saldo ao longo do dia, não sendo admitido, a qualquer momento, saldo a descoberto. Deverão ainda ser instituídos horários para o lançamento do resultado financeiro oriundo das diferentes câmaras de liquidação. O Banco Central estabelecerá contratos com os titulares das contas de reservas bancárias e com as câmaras de liquidação, onde estarão fixados claramente os deveres e as responsabilidades das partes. $\rightarrow$ Irrevocabilidade e incondicionalidade dos pagamentos (finality)

Os sistemas de transferência de grandes valores, seja pelo valor bruto em tempo real (LBTR), seja de liquidação defasada pelo valor liquido (LDL), devem garantir que as ordens de pagamentos, após serem efetivadas, sejam irrevogáveis e incondicionais.

No caso dos sistemas em LBTR operados pelo Banco Central, a efetivação da ordem dar-se-á com o efetivo lançamento na conta de reservas bancárias. No caso das câmaras de liquidação LDL, a efetivação ocorrerá após atendidos os requisitos estabelecidos pela gestora e a confirmação da ordem pela câmara. As câmaras de liquidação privadas deverão ter mecanismos para assegurar a liquidação financeira das ordens, mesmo no caso de um eventual não recebimento por parte de algum participante.

\section{$\rightarrow$ Participantes com pleno conhecimento dos riscos envolvidos nos sistemas que operam}

Os regulamentos das diferentes câmaras de liquidação devem ser explícitos quanto às responsabilidades do participante e da própria câmara, assim como devem estar claramente definidas as responsabilidades do Banco Central.

$\rightarrow$ Redução da defasagem entre a contratação de operações e sua efetiva liquidação financeira (lag de liquidação)

A introdução de um sistema de liquidação bruta operando em tempo real deverá constituir plataforma para a redução da defasagem de tempo entre a contratação e liquidação de todas as transações importantes, reduzindo sobremaneira o risco no Sistema de Pagamentos Brasileiro.

Esta redução é particularmente desejada no caso da liquidação de Bolsas e no caso das transações interbancárias que atualmente circulam, em sua maioria, pelo sistema de compensação do Banco do Brasil.

\section{$\rightarrow$ Adoção de mecanismos de administração de riscos e contingência nos sistemas re- levantes}

As câmaras de liquidação sistemicamente importantes deverão adotar mecanismos eficientes para a redução de risco e dispor de esquemas de contingência operacional para dar curso às suas operações diárias. Quanto aos mecanismos de redução de risco, deverão estar previstos, entre outros: 
- Estabelecimento de limites bilaterais pelos participantes e multilaterais pelas câmaras de liquidação;

- O princípio da entrega contra pagamento (DVP);

- Aporte de garantias;

- Mecanismos de repartição de perdas;e

- Condições para a execução tempestiva e segura das garantias.

\section{$\rightarrow$ Adoção de Base legal adequada}

O Banco Central deverá fazer todos os esforços para a alteração das regulamentações que se fizerem necessárias a fim de permitir que as diretrizes acima enumeradas sejam alcançadas.

Dentre os pontos de atenção da autoridade monetária estão:

- O reconhecimento da compensação multilateral;

- Alteração nos dispositivos legais que permitam a segura execução das garantias.

\section{Principais alterações divulgadas até o presente momento}

As alterações motivadas pela reformulação do Sistema de Pagamentos Brasileiro são de duas ordens. A primeira está relacionada à infra-estrutura de comunicação necessária para a implantação dos novos procedimentos, seja entre as câmaras de liquidação e os participantes, seja no próprio gerenciamento da conta de reservas. A segunda procura detalhar os novos procedimentos operacionais que serão adotados pelas câmaras de liquidação.

\section{Infra-estrutura de comunicação}

As alterações introduzidas pela reestruturação do Sistema de Pagamentos Brasileiro irão elevar de forma considerável o volume de troca de informações entre os participantes e o Banco Central e entre os participantes e as câmaras de liquidação, tornando impossível a manutenção da atual rede de comunicação.

Conforme recomendado pelo B.I.S., o sistema deve assegurar alto grau de segurança e credibilidade operacional, além de contar com procedimentos de contingência para pontual finalização do processamento diário. Adicionalmente, os sistemas LBTR demandam extrema agilidade na troca de comandos e/ou confirmações; se assim não fosse, não poderiam ser chamados de sistemas em "Tempo Real".

Com o objetivo de reformular a presente rede de comunicação e estabelecer padrões modernos e seguros de troca de informações, o Banco Central formou três grupos de trabalho, reunindo representantes dos bancos, das associações de classe, das câmaras de liquidação e do Banco Central.

O primeiro grupo estuda a rede de comunicação a ser implantada, enquanto o segundo é responsável por estabelecer os padrões e os formatos das mensagens que transitarão por esta rede.

O grupo de "Redes de Comunicação" tem por objetivos especificar a arquitetura da rede, identificando potenciais provedores, definir esquemas de contingência e de dualidade, definir a estrutura de segurança e estabelecer a forma de migração da rede atual para a nova rede.

O grupo "Padrão de Mensagens" deve estabelecer um padrão de mensagens que atenda todos os requisitos de funcionalidade, de segurança, de flexibilidade e de conversão para os padrões internacionais.

O progresso nos trabalhos de ambos os grupos é periodicamente publicado pelo Banco Central e constitui peça fundamental na especificação das alterações necessárias nos sistemas das instituições financeiras e das câmaras de liquidação.

\section{Alterações nas câmaras de liquidação}

Serão criadas ou reformuladas as seguintes câmaras de liquidação, agrupadas segundo o seu modelo de operação:

Sistemas de Liquidação Bruta em Tempo Real (LBTR), sob a governança e operacionalização do Banco Central:

- STR (Sistema de Transferência de Reservas);

- SELIC

Sistemas de Liquidação Defasada pelo Valor Liquido(LDL), sob a governança e operacionalização dos participantes:

- CIP (Câmara Interbancária de Pagamentos)

- Câmara de Câmbio

- CBLC

- BM\&F

- CETIP 
O Banco Central pretende reduzir drasticamente o trânsito de valores relevantes pela COMPE (Sistema de Compensação de Cheques do Banco do Brasil). Para tanto, estabeleceu que a instituição que pretenda participar da COMPE em determinada data deverá depositar como encaixe compulsório a média semanal bruta dos valores sacados contra a instituição que ultrapassarem individualmente o valor $\mathrm{R} \$ 5.000,00$.

O objetivo desta medida é reduzir a participação da COMPE no valor total dos recursos transacionados, transferindo os valores relevantes para sistemas seguros como o STR ou a CIP. Esta medida baseia-se no fato de que a COMPE deverá ter sua importância sistêmica reduzida a fim de não ser enquadrada na MP 2040 e ter de oferecer garantia de liquidação aos seus participantes. Adicionalmente, por depender de trânsito de documentos, cheques, boletos de cobrança etc., tem elevada defasagem de tempo até a liquidação final das transações.

A seguir serão descritas as principais características ou alterações definidas até o presente momento para cada um dos sistemas ou câmaras de liquidação.

$\rightarrow$ Câmaras de liquidação - LBTR

$\rightarrow$ Sistema de Transferência de Reservas (STR)

Sistema gerenciado e operacionalizado pelo Banco Central. Deverá processar em tempo real, liquidando "operação a operação" (LBTR) as transferências de fundos comandas pelos titulares. Terão acesso ao STR todas as instituições titulares de contas de reservas bancárias. Serão aceitas apenas as ordens de crédito e o sistema verificará a existência de saldo suficiente para suportar os lançamentos na conta do requisitante. O STR funcionará com níveis de prioridade A, B, C e D para os lançamentos.

Nível A: transferências para as câmaras de liquidação e saques de numerário.

Nível B: Transferências para o SELIC.

Nível C e D: demais lançamentos, a critério da instituição.

As diversas câmaras privadas LDL deverão, obrigatoriamente, processar a liquidação final do saldo multilateral através do STR. O processamento de uma câmara de liquidação LDL se dará em um intervalo de tempo chamado janela de liquidação e terá prioridade máxima quando comparada aos lançamentos de outras origens.

A instituição terá liberdade para estabelecer níveis de prioridade $\mathrm{C}$ ou $\mathrm{D}$ para os demais lançamentos. $\mathrm{A}$ instituição poderá ainda, a qualquer momento, cancelar lançamentos ou alterar a prioridade dentro da fila cronológica de pendências do sistema.

$\mathrm{Na}$ hipótese de ausência de saldo na conta de reservas bancárias, o STR poderá manter pendente (e eventualmente processar mecanismos de otimização) ou rejeitar o lançamento. As transferências serão consideradas finais e irrevogáveis a partir da concretização do débito na conta do participante. As ordens de crédito que envolverem clientes das instituições financeiras serão aceitas até às 16:00hs. Esta medida tem por objetivo melhorar o gerenciamento da conta de reservas, evitando movimentos inesperados em período de menor nível de atividade do mercado monetário.

\section{Sistema Especial de Liquidação e Custódia (SELIC)}

O SELIC passará a operar sob o conceito de liquidação pelo valor bruto em tempo real (LBTR). Da mesma forma que o STR, o SELIC continuará a ser gerenciado e operacionalizado pelo Banco Central.

O SELIC aceitará comandos das $8: 00$ hs às 19:00hs, podendo este horário ser estendido a critério do Banco Central. O sistema operará com estrita observância do princípio de entrega contra pagamento (DVP) em bases brutas.

Em linhas gerais, o processamento terá inicio após o lançamento/confirmação da operação pelas partes no sistema. O SELIC, então, verificará a custódia do título negociado, procedendo ao bloqueio da quantidade negociada. O segundo passo consistirá na verificação do limite concedido pelo banco liquidante. Atendidas as prerrogativas, o SELIC encaminha para o STR o pedido de verificação de saldo na conta do participante ou liquidante. Havendo saldo suficiente, a operação será liquidada com a movimentação simultânea dos títulos e dos fundos. Esta liquidação será considerada final, irrevogável e irretratável.

Sem prejuízo do princípio de entrega contra pagamento, estarão disponibilizadas as seguintes facilidades no sistema:

$\rightarrow$ Limite de 30 trinta minutos para confirmação pela contraparte de lançamento efetuado pela parte;

$\rightarrow$ Pendência de títulos até o horário limite a ser determinado diariamente pelo SELIC; 
$\rightarrow$ Mecanismo de otimização das pendências de títulos;

$\rightarrow$ Identificação de conjunto de operações para lançamento simultâneo de operação, operação a operação, pelo valor bruto;

$\rightarrow$ Contas especiais de liquidação, para as garantias e a custódia das Câmaras de liquidação (LDL);

$\rightarrow$ Operações de corretagem onde o corretor não assumirá qualquer risco;

$\rightarrow$ Volta das operações compromissadas e liquidação de ofertas públicas comandadas pelos participantes em horário mais conveniente para as partes;

$\rightarrow$ Operações de redesconto de títulos junto ao Banco Central

\section{Câmaras de Liquidação Privadas - LDL}

A Medida Provisória n. 2040 dispõe que nos subsistemas em que o volume e a natureza dos negócios, a critério de Banco Central, forem capazes de oferecer risco à solidez e ao normal funcionamento do Sistema Financeiro Brasileiro, as câmaras de compensação ou liquidação de valores ou ativos deverão assumir a posição de contraparte central garantidora para fins de liquidação das obrigações realizadas por seu intermédio. Para tanto, as câmaras "sistemicamente importantes" deverão contar com mecanismos e salvaguardas que permitam assegurar a certeza de liquidação das operações nelas compensadas e liquidadas. Dentre os mecanismos admitidos temos, entre outros, dispositivos de segurança de acesso, regras de controle de risco, de contingência e de compartilhamento das perdas entre os participantes, além de mecanismos para execução direta das posições de custódia e das garantias aportadas.

Será admitida, sem prejuízo do princípio da entrega contra pagamento (DVP), a compensação multilateral das obrigações no âmbito de uma mesma câmara. A liquidação final do saldo dos participantes deverá ser processada diretamente nas contas de reservas junto ao Banco Central, não sendo admitida a liquidação em qualquer outro subsistema. Desta forma, todas as câmaras que se enquadrarem na MP 2.040 deverão, obrigatoriamente, solicitar ao Banco Central a abertura de conta de liquidação financeira.
As contas de liquidação financeira das câmaras LDL no Banco Central abrirão e encerrarão o dia com saldo sempre igual a zero.

As câmaras de liquidação LDL contarão com horários de liquidação próprios onde inicialmente receberão os valores devidos por seus participantes com saldo liquido devedor para posteriormente creditar a conta de reservas bancárias dos participantes com saldo liquido credor. Este intervalo de tempo será chamado de "janela de liquidação" e cada câmara terá sua janela de liquidação distinta no STR. Todas as câmaras de liquidação deverão encerrar seus processamentos antes do horário de encerramento do sistema de movimentação das contas de reservas (STR) que está previsto para 19:00hs.

As câmaras de liquidação LDL estão divididas em câmaras que processam tão somente pagamentos (câmaras de pagamentos) e câmaras que processam ativos e pagamentos (câmaras de liquidação de ativos).

As câmaras de pagamentos serão responsáveis por garantir, ao longo do dia de processamento, a certeza de concretização do crédito, no STR, ao participante, ao final da janela de liquidação da câmara. As câmaras de liquidação de ativos, além de garantir o princípio da entrega contra pagamento (DVP), deverão contar com mecanismos que evitem ao máximo o não cumprimento das obrigações da câmara de liquidação devido à falha na entrega de ativos ou de fundos pelos participantes.

Até o presente momento, sabe-se que a Câmara Interbancária de Pagamentos (CIP) e, talvez, a Câmara de Câmbio, serão câmaras de liquidação de pagamentos conforme definido anteriormente. As câmaras de liquidação de ativos serão a CBLC, a BM\&F e a CETIP.

Na seqüência, serão destacados os procedimentos operacionais e as características já definidas ou em discussão para cada uma das câmaras.

\section{Câmara Interbancária de Pagamentos (CIP)}

Esta câmara de liquidação terá por objetivo efetuar as transferências financeiras entre Bancos e entre clientes destes bancos quando o valor ou a urgência na disponibilização dos fundos impossibilite o trânsito pela compensação. A CIP será gerida pela Federação dos Bancos (FEBRABAN) e terá como provedor 
operacional a CETIP.

$\mathrm{Na} \mathrm{CIP}$, as ordens de transferências de fundos serão comandadas pelo ordenante e confirmadas ao longo do dia de processamento para o ordenante e para o beneficiário dos fundos. A CIP contará com esquemas de depósito inicial obrigatório e limites operacionais necessários para a confirmação final da ordem por parte da câmara de liquidação mesmo antes da efetiva disponibilização dos fundos na conta de reservas bancárias dos envolvidos. A seguir serão enumerados as principais características e procedimentos operacionais divulgados na minuta de regulamento operacional da câmara:

$\rightarrow$ Será requerida dos participantes a constituição de um depósito inicial, na conta de reservas bancárias da câmara, compatível com o volume de fundos demandado pelo participante;

$\rightarrow$ A câmara verificará "em tempo real" a existência de fundos suficientes na conta do participante na câmara onde foi constituído o depósito;

$\rightarrow$ Serão disponibilizados mecanismos de otimização de lançamentos onde o objetivo será compensar o maior número de lançamentos entre os participantes;

$\rightarrow$ A CIP funcionará das 8:00 às 16:45hs;

$\rightarrow$ O processamento ocorrerá em dois ciclos, ciclo principal liquidando até às 16:00hs no STR e ciclo complementar liquidando até às 16:45 no STR.

A vantagem da CIP em relação ao STR parece ser a possibilidade de compensação de lançamentos bilaterais e multilaterais em tempo real e, por conseguinte, a redução do valor exigido a título de depósito inicial. Os lançamentos não aceitos pela CIP, em um determinado momento, permanecerão pendentes, aguardando confirmação até o final do ciclo principal. Neste sentido, quanto maior o número de lançamentos pendentes, maior será a possibilidade de ocorrerem tais compensações. Todavia, esta "vantagem" dependerá da definição dos mecanismos de otimização que estarão também disponíveis no STR.

\section{Câmara de Câmbio}

A câmara de liquidação (LDL) de câmbio processará a liquidação dos contratos do mercado interbancário de câmbio pelo saldo líquido multilate- ral. A liquidação das moedas nacional e estrangeira deverá ser feita simultaneamente durante a janela de liquidação do STR (moeda nacional) e Chips/Fed wire (moeda estrangeira).

A câmara será gerida pela Federação dos Bancos (FEBRABAN) e operacionalizada pela BM\&F. Através da liquidação simultânea das moedas nacional e estrangeira, a câmara terá por princípio garantir que o pagamento em um moeda somente ocorra após a confirmação do crédito da outra moeda na conta da câmara. Neste sentido, o principal estará sempre garantido e, na hipótese de quebra de um participante, bastará a câmara realizar a venda das reservas em uma moeda para honrar o pagamento na outra moeda.

\section{Companhia Brasileira de Liquidação e Custódia (CBLC)}

A CBLC está se preparando para ser uma grande câmara de liquidação de ativos, não apenas de ações e de opções negociadas na BOVESPA, mas também de títulos de renda fixa públicos e privados negociados no SISBEX (Sistema de Negociação Eletrônica da Bolsa do Rio). Como câmara de ativos, a CBLC terá como princípio básico a manutenção da entrega contra pagamento, simultânea e irrevogável. A CBLC é a câmara mais organizada até o presente momento, tendo realizado diversas reuniões com o mercado para discussão dos novos procedimentos operacionais. Dentre os procedimentos em discussão pode-se destacar os seguintes:

$\rightarrow$ Liquidação financeira em reservas bancárias em $\mathrm{D}+3$;

$\rightarrow$ A custódia dos títulos estará liberada imediatamente após o ciclo de liquidação em D+3;

$\rightarrow$ Serão exigidos depósitos de garantia para todos os mercados, inclusive os mercados à vista;

$\rightarrow$ Mecanismo de repartição de perdas híbrido, com preferência pela colaterização (constituição de garantias por parte do detentor da posição);

$\rightarrow$ Mecanismos de redução de falhas na entrega de papéis e na liquidação financeira, tais como banco de empréstimo voluntário e compulsório e entrega de título substitutivo, entre outros;

$\rightarrow$ Custódia para títulos públicos e conta especial no SELIC para a transferência de papéis custodiados no SELIC para a CBLC. 


\section{Central de Custódia e Liquidação Financeira de Títulos (CETIP)}

Dada a sua importância dentro do sistema financeiro brasileiro, a CETIP deverá processar sua liquidação diária diretamente no STR. A CETIP está constituindo uma câmara de liquidação LDL de ativos para oferecer garantia de liquidação às operações do mercado secundário de títulos de Renda Fixa. A Central estará focada na liquidação de CDBs e de Debêntures, além de oferecer a liquidação de operações cursadas pelo SIM (Sistema Eletrônico de Títulos Públicos). As operações cursadas pela Central serão liquidadas pelo valor líquido multilateral no final do dia.

A CETIP deverá funcionar como uma depositária de custódia e não oferecerá garantias para as emissões, para os resgates ou para o pagamento de juros dos papéis registrados em seus sistemas. As câmaras de liquidação LDL garantem o risco de liquidação das operações. O risco contido nas emissões e resgates de um determinado título é risco de crédito, ou seja: é o risco de o emissor não ter capacidade financeira para honrar o resgate do título. Cabe à depositária de custódia garantir apenas o princípio da entrega contra pagamento (DVP). Todavia, a incerteza na liquidação destas operações pode afetar o funcionamento do mercado, e o risco será tanto maior quanto maior for o tempo decorrido entre a contratação e efetiva liquidação da operação. Neste sentido, as operações registradas no CETIP deveriam ser liquidadas, preferencialmente, uma a uma diretamente no STR. O Banco Central permitiu que, além da liquidação bruta no STR, o CETIP ofereça a facilidade de liquidação pelo valor liquido bilateral (parte $x$ contraparte) das operações confirmadas até um determinado período de tempo ou horário do dia. O horário limite para liquidação do valor bilateral está em processo de definição junto ao Banco Central.

\section{Bolsa de Mercadorias e Futuros (BM\&F)}

A BM\&F já atende várias das diretrizes determinadas pelo Banco Central para as câmaras de liquidação de ativos (LDL). A BM\&F é contraparte central garantidora para a maioria das operações registradas em seus sistemas, exige garantias dos participantes e tem mecanismo de repartição de perdas razoavelmente definido. No entanto, a reestruturação do SPB deverá exigir reformulações em seus procedimentos.

A principal mudança operacional é a liquidação diretamente na conta de reservas bancárias em $D+1$ (dia útil seguinte). A janela de liquidação da BM\&F no STR está prevista para o período das 14:30 às 15:10hs. A BM\&F estará liquidando diretamente na conta de reservas dos membros de compensação. Os membros de compensação que não sejam bancos detentores de conta de reservas bancárias deverão indicar um outro membro com esta característica que será responsável por sua liquidação. A BM\&F está planejando desenvolver seus sistemas para prestar informações sobre liquidação financeira e margem de garantia ao longo do dia de negociação. O sistema de risco está sendo adaptado para a nova realidade e deverá calcular o risco pelo valor do portifólio consolidado do cliente. O sistema de cálculo de riscos da BM\&F está subdividido em dois sistemas distintos: o primeiro para cálculo do risco envolvido nos ativos ilíquidos (swaps, opções flexíveis etc.) e o segundo para cálculo do risco de ativos líquidos (Futuros de dólar, DI, coupon cambial etc.). As corretoras terão, ainda, acesso a simuladores de margem para calcular as margens de garantia de seus clientes antes da disponibilização da informação pela BM\&F.

\section{Cronograma de Reestruturação do Sistema de Pagamentos Brasileiro}

O Banco Central do Brasil divulgou, no dia 20 de setembro de 2001, a Circular 3.060, contendo:

- as regras de funcionamento da conta Reservas Bancárias, que começa a ser monitorada em tempo real pelo Bacen, a partir de 22/04/2002, não podendo ter saldo negativo a partir de 24/06/2002; e

- o cronograma de migração do atual sistema de comunicação das instituições financeiras com o Bacen relativo às movimentações da conta Reservas Bancárias.

De acordo com este cronograma, somente em 22 de abril de 2002 é que a implantação será definitiva, embora o Banco Central tenha dado um prazo ainda maior de transição para as instituições se adaptarem à exigência de que não haja saldo negativo, ao longo do dia, na conta de reservas bancárias. 
Por esse prazo de transição, entre os dias 22 de abril e 19 de maio de 2002 as instituições poderão apresentar saldo negativo intradia de até $100 \%$ de seu patrimônio líquido ajustado (PLA). Do dia 20 de maio a 21 de junho de 2002, o percentual cai para $50 \%$ do PLA. A partir de 24 de junho de 2002, as instituições não poderão mais ter saldo negativo ao longo do dia, na conta reservas bancárias.

Desse modo, o cronograma de testes ficou definido da seguinte forma:

- testes de infraestrutura foi até 26/09/2001;

- testes de sistemas foi até 25/03/2002;

- testes de carga foi até 27/03/2002;

- testes de operações diárias previsto para até 16/ 04/2002; e

- testes do dia de implantação previsto para até 17/04/2002.

\section{OS POSSÍVEIS IMPACTOS DO NOVO SPB NAS INSTITUIÇÕES FINANCEIRAS}

O Banco Central está promovendo uma profunda alteração na forma com que os pagamentos são feitos no Brasil. Os bancos já começaram a se preparar para as mudanças, revendo produtos, processos e sistemas, pois a maneira como os bancos se relacionam com o Banco Central será modificada.

\section{As modificações}

Todos os sistemas deverão estar equipados com modernos e eficientes instrumentos de gerência de riscos. Com isso, terão capacidade de absorver posições devedoras causadas por participantes insolventes, quando o Banco Central rejeitar seus lançamentos devido à insuficiência de fundos em reservas bancárias. Todas as câmaras de compensação deverão contar com adequados mecanismos de contingência que permitam o curso normal das transações na hipótese de problemas operacionais (BCB, 1999).

A partir de meados de 2002, o Banco Central estará administrando as contas individuais de Reservas Bancárias ao longo de todo o dia, não permitindo saques a descoberto em nenhum instante. Lançamentos que resultariam em saldo devedor serão rejeitados. Implementará também um sistema que possibilitará pagamentos instantâneos entre instituições, o Sistema de Transferência de Reservas
(STR). Tal sistema operará em regime de liquidação bruta em tempo real (LBTR). Os bancos deverão desenvolver produtos para levar essa opção aos seus clientes. As transferências serão sempre a crédito de outra instituição, lançadas pelo banco remetente (debitado). Quando um cliente solicitar transferência e houver saldo em Reserva Bancária, as transferências serão feitas instantaneamente; quando não, a transação ficará pendente, aguardando a chegada de créditos.

Para facilitar a administração de caixa dos bancos, o STR possibilitará a formação de filas de pagamentos, conforme prioridades e horário de entrada dos lançamentos. O atual ambiente de registro e liquidação das operações com Reservas Bancárias e títulos públicos, o Selic, será um sub-sistema desse STR, com novas funcionalidades. Uma destas é a possibilidade de os bancos obterem Reserva Bancária diretamente do Banco Central via redesconto de títulos públicos federais, quando intradia a custo zero e por prazos maiores conforme as condições da época (hoje, o redesconto com garantia de títulos custa Selic+6\%aa).

Também faz parte da reestruturação a constituição de câmaras mais seguras quanto à finalização das operações para os ambientes considerados sistemicamente importantes, as chamadas clearings. Tais câmaras deverão garantir a certeza de liquidação, equivalente ao conceito de finality, onde as operações e respectivas liquidações financeiras têm caráter irrevogável e incondicional. Para que estas possam assegurar tais condições, as instituições participantes serão obrigadas a depositar garantias. Essas clearings farão liquidações financeiras em Reserva Bancária e terão horários específicos de lançamentos no STR. Quando as clearings forem lançar seus resultados, via STR, as instituições deverão ter saldo suficiente para eventuais débitos. Caso alguma não consiga fundos, a clearing executará as garantias e reprocessará o movimento excluindo aquele participante.

Além de garantirem as operações, a liquidação financeira das clearings será pelo saldo líquido de cada participante, e com alguma defasagem temporal em relação ao fechamento da operação. Com isto, o número de transferências diretas entre bancos será bastante diminuído, pois as operações em cada ambiente terão uma contraparte central. Essa forma de liquidação, conhecida internacionalmente como DNS (deferred 
net settlement), tem sido chamada pelo Banco Central de LDL (liquidação diferida líquida).

Desta maneira, a clearing de pagamentos deverá executar as liquidações em reserva no final do mesmo dia (Dzero); a BM\&F continuará liquidando no dia útil seguinte $(D+1)$, mas em reserva; a CBLC continuará liquidando em D+3 ( $3^{\circ}$ dia útil subseqüente), também em reserva. Quanto às outras clearings em constituição, títulos públicos, títulos privados e câmbio, ainda não há definição da defasagem que utilizarão.

Nesse novo ambiente, a dinâmica de administração do caixa das instituições será dramaticamente alterada. Atualmente, todos os pagamentos dos diversos agentes econômicos são finalizados via moeda corrente ou compensação bancária, e apenas instituições financeiras realizam transações com liquidação em Reserva Bancária. Assim, o saldo em reserva só se altera em função das operações com títulos públicos e operações em reserva (compromissadas e CDI-Reserva) contratadas no próprio dia, ou por frustração de algum lançamento previamente contratado. Os demais lançamentos, como por exemplo, das operações de câmbio, são previamente conhecidos. As operações com clientes pressupõem liquidação via compensação bancária no início e no vencimento para quase todos os produtos. Exceções seriam desencaixe de numerário e compras de títulos públicos, situações não muito freqüentes e em que a reserva bancária é considerada na formação de preço.

As áreas responsáveis por títulos públicos e Reservas Bancárias (mesas de open) realizam suas operações baseadas em informações produzidas por outra, usualmente chamada de Gestão da Liquidez ou similar. Atualmente, estas áreas têm um dia inteiro para produzir um saldo de Reservas Bancárias projetado para o dia seguinte, capturando informações de diversas fontes, algumas prévias, outras definitivas.

Dado o alto grau de automação dos processamentos e a experiência acumulada por muitos anos de prática, onde as coisas aconteceram quase sempre da mesma forma, as prévias são confirmadas com poucas alterações. Isso traz um conforto para os operadores, que podem utilizar o dia todo para realizar transações em Reserva Bancária. Com as alterações vislumbradas surgirá uma nova figura na estrutura organizacional dos bancos, o "grupo de pilotos da reserva". A principal atribuição dessa equipe será apurar continuamente o saldo em Reserva e monitorar, se possível de maneira antecipatória, os lançamentos vindos das clearings. Deverão ser consultados antes de qualquer movimentação a débito em Reserva, seja para atender solicitação de clientes ou compra de títulos públicos. Serão responsáveis, também, pela administração das filas internas de lançamentos, seja no STR ou nas clearings. (JORDÃO, 2001, p.3-5)

A modificação proposta pelo projeto de reestruturação do Sistema de Pagamentos Brasileiro tem principalmente os seguintes objetivos:

a) minimizar o risco sistêmico;

b) evitar assunção de riscos por parte do Banco Central; e

c) melhorar a classificação de risco do Brasil perante investidores internacionais.

A seguir são apresentadas algumas modificações decorrentes da implantação do projeto:

- dependendo do valor da operação, serão permitidos o envio / recebimento de fundos com valorização para o mesmo dia;

- haverá necessidade de gerenciamento do fluxo de caixa; e

- os horários para serviços de pagamentos e transferências poderão ser alterados, bem como os prazos para liquidação, de acordo com o valor das operações.

Em relação ao funcionamento das contas reservas bancárias:

- não será admitido saldo negativo - o saldo será monitorado em tempo real;

- haverá um sistema de prioridades para lançamento das movimentações; e

- as movimentações não poderão ser canceladas apenas uma operação contrária poderá restituir o valor transferido com erro.

\section{Prováveis impactos das mudanças}

O atual projeto de reestruturação do sistema de pagamentos brasileiro deverá provocar inúmeras mudanças no funcionamento do sistema financeiro, no relacionamento entre bancos e seus clientes e na própria gestão financeira nacional. Além disso, existirão efeitos macroeconômicos relativos ao risco-país. 
Em primeiro lugar, a administração financeira dos bancos deve priorizar a gestão das reservas bancárias, que deverá ser monitorada em uma base contínua ao longo do dia, pois não serão admitidos saques a descoberto nesta conta. Ademais, a recomposição da liquidez de uma instituição financeira pode significar custos de oportunidade razoavelmente elevados, dependendo das condições de funcionamento do mercado monetário. Os produtos e serviços bancários tradicionais, tanto na captação quanto na aplicação de recursos, devem ser redesenhados, no que afetar a gestão de liquidez dos bancos, em termos de preços, limites de utilização, horários de movimentação, custos e riscos. Novos produtos e serviços podem ser criados, em decorrência da maior rapidez e segurança no sistema de pagamentos. Por fim, os bancos deverão ser mais seletivos na avaliação de crédito de seus clientes e sobretudo de seus parceiros bancários.

Em segundo lugar, instituições financeiras não bancárias independentes (corretoras e distribuidoras de valores, financeiras, bancos de investimento), sem acesso direto à conta de reservas bancárias, serão afetadas em seus negócios, na medida em que tais transações dependerem da disponibilidade de reservas de seu banco liquidante/custodiante. Esta restrição é particularmente relevante na negociação de títulos públicos federias, podendo acarretar a diminuição da participação das instituições independentes no giro de títulos da dívida mobiliária federal.

Em terceiro lugar, o relacionamento dos bancos com seus clientes, pessoas jurídicas e físicas, devem experimentar mudanças, as quais, muito provavelmente determinarão modificações na própria gestão de caixa das grandes empresas. Práticas tradicionais no giro financeiro dos negócios deverão ser abandonadas ou sofrer mudanças para se adaptarem às novas regras do Sistema Nacional de Pagamentos (MOURA, 2000, p.16-17).

Por último, os efeitos das citadas mudanças não se esgotam no nível das empresas e do sistema financeiro. Existem também impactos macroeconômicos potencialmente importantes. As mudanças previstas apontam no sentido de fortalecimento dos mecanismos de liquidação financeira na economia brasileira, aproximando-os dos melhores padrões internacionais. Isto certamente poderá contribuir para reduzir o risco de operar no Brasil, nos mercados monetários, financeiros, de capitais, de câmbio e de futuros. 0 efeito final poderá ser uma redução no risco-país e até mesmo uma diminuição da taxa de juros.

Portanto, por todos estes efeitos, as citadas mudanças apontam na direção correta de fortalecimento e modernização da infra-estrutura financeira da economia nacional (MOURA, 2000, p.18).

\section{Impactos do novo sistema de pagamentos no mercado financeiro}

Os Mercados de ações, derivativos, renda fixa e títulos serão afetados de modo diferente. Muitas das mudanças ainda estão em discussão.

\section{Cash Management - Gestão em tempo real}

O novo Sistema de Pagamentos Brasileiro (SPB) trará mudanças para o dia-a-dia dos bancos, clientes e fornecedores. Existirá uma reestruturação na forma de interação dos mercados e provocará a revisão dos procedimentos empresariais de gestão do fluxo de caixa.

A gestão do fluxo de caixa exigirá atenção na disponibilidade de recursos em Reservas Bancárias - não mais em saldos contábeis. Pagamentos e transferências em tempo real feitos sob previsão de entrada de recursos devem ser evitados, pois podem significar custo de dinheiro por um dia.

As transações previamente agendadas terão um custo inferior às solicitadas na data de sua liquidação $(D+0)$, pois a demanda por reservas bancárias em $\mathrm{D}+0$ deve aumentar o custo financeiro das transações, inclusive ao longo do dia. As aplicações/ resgates de fundos e liberações de crédito ocorrerão diretamente em reserva. Resgates de grandes volumes deverão ser agendados para garantir a disponibilidade de recursos na conta Reservas Bancárias. Os horários para serviços de pagamentos e transferências deverão ser alterados. As novas modalidades de pagamento terão tarifas diferenciadas. Os sistemas bancários integrados e aplicativos on line favorecerão a gestão financeira no novo cenário.

A seguir serão apresentados quadros comparativos referentes aos produtos do mercado financeiro, confrontando alguns aspectos atuais e suas expectativas futuras, decorrentes da implantação do novo sistema de pagamentos: 


\section{Derivativos}

\begin{tabular}{|l|l|}
\hline \multicolumn{1}{|c|}{ Atualmente } & \multicolumn{1}{|c|}{ Expectativa Futura } \\
\hline $\begin{array}{l}\text { Liquidação Financeira } \\
\text { confirmada só um dia após o } \\
\text { pagamento }(\mathrm{D}+1)\end{array}$ & $\begin{array}{l}\text { Liquidação Financeira com } \\
\text { confirmação no mesmo dia. }\end{array}$ \\
\hline $\begin{array}{l}\text { BM\&F (Depto. de Liquidação) } \\
\text { é a liquidante das operações, } \\
\text { mas não é a garantidora das } \\
\text { operações. }\end{array}$ & $\begin{array}{l}\text { BM\&F se tornará uma } \\
\text { Câmara de Liquidação }\end{array}$ \\
\hline
\end{tabular}

\begin{tabular}{|l|l|}
\multicolumn{2}{|c|}{ Ações } \\
\hline Atualmente & Expectativa Futura \\
\hline $\begin{array}{l}\text { Liquidação Física e } \\
\text { Financeira em diferentes } \\
\text { momentos. }\end{array}$ & $\begin{array}{l}\text { Liquidação Física e } \\
\text { Financeira em um mesmo } \\
\text { momento Conceito Entrega X } \\
\text { Pagamento. }\end{array}$ \\
\hline $\begin{array}{l}\text { Ciclo de Liquidação } \\
\text { encerrado em 5 dias (D + 5) } \\
\text { (desbloqueio das ações). }\end{array}$ & $\begin{array}{l}\text { Redução do ciclo de } \\
\text { liquidação para 3 dias (D + 3). }\end{array}$ \\
\hline $\begin{array}{l}\text { Liquidação Financeira } \\
\text { confirmada só um dia após o } \\
\text { pagamento (D + 1). }\end{array}$ & $\begin{array}{l}\text { Liquidação Financeira com } \\
\text { confirmação no mesmo dia. }\end{array}$ \\
\hline $\begin{array}{l}\text { CBLC é liquidante das } \\
\text { operações, mas não é } \\
\text { garantidora das operações. }\end{array}$ & $\begin{array}{l}\text { CBLC se tornará uma } \\
\text { Câmara de Liquidação } \\
\text { (Clearing). }\end{array}$ \\
\hline
\end{tabular}

Como se pode observar, se estas mudanças ocorrerem como o previsto, conduzirão a grandes alterações no funcionamento do sistema financeiro nacional, produzindo sérias conseqüências no relacionamento das instituições financeiras com seus clientes, pessoas físicas e jurídicas, e com a sociedade em geral, afetando os atuais procedimentos, rotinas e práticas da gestão financeira brasileira.

\section{ANÁLISE DO PROJETO SPB: VANTAGENS E DESVANTAGENS}

O Sistema de Pagamentos Brasileiro está projetado para entrar em vigor em abril de 2002, segundo planos do Banco Central do Brasil.
Renda Fixa - Títulos Privados

\begin{tabular}{|l|l|}
\hline \multicolumn{1}{|c|}{ Atualmente } & \multicolumn{1}{c|}{ Expectativa Futura } \\
\hline $\begin{array}{l}\text { Liquidação Financeira } \\
\text { através de sistema próprio. }\end{array}$ & $\begin{array}{l}\text { Liquidação Financeira } \\
\text { através de sistema próprio } \\
\text { adaptado à nova sistemática, } \\
\text { a ser definida. }\end{array}$ \\
\hline $\begin{array}{l}\text { Liquidação Financeira } \\
\text { ponfirmada só um dia após o }\end{array}$ & $\begin{array}{l}\text { Liquidação Financeira com } \\
\text { confirmação no mesmo dia. }\end{array}$ \\
\hline $\begin{array}{l}\text { CETIP é liquidante das } \\
\text { operações, mas não é } \\
\text { garantidora das operações. }\end{array}$ & $\begin{array}{l}\text { CETIP se tornará uma } \\
\text { Câmara de Liquidação } \\
\text { (Clearing). }\end{array}$ \\
\hline
\end{tabular}

\section{Títulos Públicos Federais}

\begin{tabular}{|l|l|}
\hline \multicolumn{1}{|c|}{ Atualmente } & \multicolumn{1}{c|}{ Expectativa Futura } \\
\hline $\begin{array}{l}\text { Liquidação Física e } \\
\text { Financeira sem confirmação } \\
\text { imediata. }\end{array}$ & $\begin{array}{l}\text { Liquidação Física e } \\
\text { Financeira em um mesmo } \\
\text { momento: Conceito Entrega } \\
\text { X Pagamento on line e em } \\
\text { tempo real. }\end{array}$ \\
\hline $\begin{array}{l}\text { O Banco Central só sabe que } \\
\text { obrigações no dia seguinte } \\
\text { pela manhã (D + 1). }\end{array}$ & $\begin{array}{l}\text { Monitoramento on line das } \\
\text { contas de reserva bancária, } \\
\text { propiciando um maior } \\
\text { controle. }\end{array}$ \\
\hline $\begin{array}{l}\text { O Redesconto (empréstimo } \\
\text { de liquidez) só é possível no } \\
\text { dia seguinte (D + 1). }\end{array}$ & $\begin{array}{l}\text { O Redesconto poderá ser } \\
\text { feito intraday (no mesmo } \\
\text { dia) ou Overnight (de um } \\
\text { dia para o outro). Não será } \\
\text { permitido saldo negativo } \\
\text { (Overdraft) na conta de } \\
\text { reservas bancárias. }\end{array}$ \\
\hline
\end{tabular}

De modo geral, este projeto se baseia no que é utilizado pelos países do G-10 e em recomendações de organismos internacionais, como o Banco Mundial, o BIS e o FMI. A dimensão do processo de reestruturação é bastante ampla e complexa. O projeto de reestruturação do sistema de pagamentos visa à adequação das práticas e sistemas brasileiros aos padrões internacionais, fortalecendo o sistema financeiro nacional, com o objetivo de dotar o país de uma eficiente estrutura para realização de pagamentos e liquidação de operações financeiras, reduzindo o chamado "risco sistêmico".

A seguir, serão apresentadas algumas vantagens e desvantagens da implantação do novo sistema de pagamentos brasileiro: 


\section{Vantagens do novo sistema de pagamentos}

Analisando-se o projeto SPB de forma global, podem ser observadas as seguintes vantagens:

\section{$\rightarrow$ Certeza de Liquidação (Princípio da Certeza de Pagamento)}

Todas as ordens de pagamentos se tornarão incondicionais e irrevogáveis (semelhante como ocorre com as Chips e Fedwire - câmaras de compensação dos Estados Unidos), uma vez liquidadas contra a conta de reserva no Sistema de Transferência de Reservas (STR) a ser operado pelo BACEN. Assim, as câmaras de compensação, ao liquidar pagamentos líquidos diferidos nas contas do Bacen, deverão oferecer condições que assegurem a liquidação de todas as operações no mesmo dia, mesmo no caso de o Bacen vir a rejeitar um lançamento contra a conta reserva de um banco.

\section{$\rightarrow$ Redução do tempo decorrido entre o início de uma transação e sua liquidação final}

Atualmente, no Brasil, uma parte significativa dos pagamentos e transferências de valores altos utilizam cheques ou outros documentos de transferências que requerem compensação de um dia para o outro.

Desse modo, com a reestruturação do sistema de pagamentos, este novo sistema operará em tempo real, com o bruto das liquidações no Bacen, fato que permitirá a redução do tempo decorrido entre o início da transação e sua liquidação final.

\section{$\rightarrow$ Adoção de Práticas Internacionais}

A adoção de práticas internacionais dará maior segurança ao investidor estrangeiro interessado em investir no país, visto que o Brasil terá um ambiente mais adequado, com práticas e procedimentos conhecidos e confiáveis.

\section{$\rightarrow$ Surgirão Novas Oportunidades}

O novo sistema de pagamentos criará novas oportunidades de negócio, ou seja, novos espaços a serem ocupados. As instituições que se antecipa- rem no fortalecimento de produtos e serviços condizentes com a nova estrutura ocuparão estes novos espaços, aproveitando essas oportunidades, fortalecendo-se em um mercado cada vez mais competitivo.

\section{Desvantagens do novo sistema de pagamentos}

Embora o processo de reestruturação do sistema de pagamentos brasileiro tenha muitos aspectos positivos, algumas questões devem ser ponderadas. Desse modo, analisando-se o projeto de forma crítica e construtiva, podem ser observadas algumas desvantagens do sistema:

$\rightarrow$ Alto Custo de Implantação do Novo Sistema

A adequação ao novo sistema de pagamentos brasileiro exigirá grandes investimentos em novos programas de computação e equipamentos. Embora os bancos maiores estejam altamente automatizados, alguns bancos de menor porte ainda operam com processos manuais.

De modo geral, os custos de implantação do novo sistema podem ser muito pesados.

\section{$\rightarrow$ Alto Custo das Reservas no STR do Banco Central}

Estima-se que o custo da manutenção de reservas brutas não sujeitas a juros no Banco Central, embora ainda não possa ser medido, provavelmente causará impacto nos lucros.

\section{$\rightarrow$ Perda de Flutuação}

No sistema de pagamentos atual, os bancos lucram com a flutuação entre os débitos e os créditos processados através do sistema de compensação. Segundo as previsões do Bacen, a perda de flutuação de um dia aumentará em $\mathrm{R} \$ 350$ milhões os custos operacionais do sistema.

\section{CONSIDERAÇÕES FINAIS}

Como podem ser observadas, as mudanças introduzidas pela reformulação do sistema de pagamentos brasileiro são extremamente significativas. 
Todas as instituições deverão estar preparadas até 22 de abril de 2002, sob pena de descontinuação dos negócios. O Banco Central deverá promover um processo de certificação a exemplo do conduzido por ocasião da virada do ano 2000, atestando a adequação dos controles e sistemas internos das instituições.

Enfim, a reestruturação do sistema de pagamentos brasileiro trará muitos benefícios para o país, proporcionando para as instituições financeiras um novo nicho de atuação, em busca de novos negócios, desafios e opor- tunidades. No entanto, até sua definitiva implementação, muitas questões ainda deverão ser observadas e solucionadas, além de outras que provavelmente surgirão.

A despeito do trabalho que todos terão pela frente, a presente reforma deverá consolidar definitivamente a posição do Brasil no mercado de capitais internacional, como uma economia moderna e sólida, propiciando a elevação dos investimentos e o crescimento econômico brasileiro, beneficiando a política monetária nacional.

\section{REFERÊNCIAS BIBLIOGRÁFICAS}

BCB (Banco Central do Brasil). Reestruturação do sistema de pagamentos brasileiro. Brasília: BCB, 2001. 13 p. Mimeografado.

MOURA, Alkimar R. Novo Sistema Nacional de Pagamentos Reduz Risco Sistêmico. Tecnologia de Crédito, São Paulo, p. 7-18, novembro 2000.

BERGH, P. V.; VEALE, J. M. Payment system risk and risk management. In: SUMMERS, B. J. (Org.) The payment system: design, management and supervision. Washington, DC: IMF, 1994. p.89-105.

BIS (Bank for International Settlements). Core principles for systemically important payment systems (Consultative Report-July 2000).
Committee on Payment and Settlement Systems. Basel: BIS, 2000.

JORDÃO, Manoel Rodrigues. Reestruturação do Sistema de Pagamentos Brasileiro - Riscos na Perspectiva dos Bancos. São Paulo, 2001.

www.bcb.gov.br

www.bis.org

www.bmf.com.br

www.cblc.com.br

www.cetip.com.br

www.federalreserve.gov

www.febraban.com.br

www.citibank.com.br 